\title{
A Perspective of Applications of Unmanned Systems in Asymmetric Warfare
}

\author{
İsa Haskologlu, A. Alparslan Eker, and Şaban Adana
}

\begin{abstract}
The history of war witnessed several technological innovations that fundemantally changed the battlefield. The ones who could adapt and improvise accordingly dominated the others and became superpowers. Along with this, asymmetric threats are increasingly beacoming a reality of our today's operating environment and most of the time technology does not seem to be the answer. Conventional armies need to adopt certain measures to counteract these threats that do not bind themselves with any kind of law. In this study, we will provide some insights on one of the measures, UAVs, and how they can be synchronized in to the overall operational planning.
\end{abstract}

Index Terms-Asymmetric warfare, face detection, knowledge management, machine learning, unmanned aerial vehicle.

\section{INTRODUCTION}

Today, the biggest challenge for the regular armies is the struggle to come up with countermeasures against asymmetric threats which are irregular, and do not follow any law.

Although countermeasures which can be taken by the countries are dependent on law procedures, asymmetric impacts are applied without any borders. The history of war witnessed several technological innovations that fundamentally changed the battlefield. The ones who could adapt and improvise acccordingly dominated the others and became superpowers. Along with this, asymmetric threats are increasingly becoming a reality of our today's operating environment and most of the time technology does not seem to be the answer. Conventional armies need to adopt certain measures to counteract these threats that do not bind themselves with any kind of law. To do this, they need to get and use information they have properly.

In this study, asymmetry, asymmetric impact and asymmetric threat will be briefly explained, then information knowledge management concept will be analyzed. After examining unmanned aerial vehicles (UAV) and their concepts of use, alternatives will be presented for their use against asymmetric threats.

\section{TERMS}

\section{A. Asymmetry-Asymmetric Impact-Asymmetric Threat}

Asymmetry, which is described as the absence of

Manuscript received May 14, 2013; revised July 19, 2013.

The authors are with Turkish Army War College, Istanbul, Turkey (e-mail ihaskologlu@gmail.com,

sabanadana@gmail.com). symmetry, can be defined as the absence of the coherence of pattern, shape, and form between two or more things. [1] To begin with explaining the concept of asymmetry it is possible to say that, it means the inconvenience of shapes locations and scales of the two different entities. Therefore, asymmetric impacts refers to influencing the enemy by employing diverse methods to gain superiority in demanded time and place through the theater. According to this, while avoiding enemy's strong points, his/her weak points are exploited.

Asymmetric threats are used by states in all ages against their enemies to influence their strength and exploit their weaknesses. Especially after World War II, some states grew disproportionately than the others. So, some inferior states and Non-State Actors (NSA) began to look for new ways rather than conventional war to overcome superior states. As a result of their efforts they spotted the critical weaknesses of their enemies and achieved to inflict casualties on super powers by exploiting their vulnerabilities. To deal with asymmetric impacts, states spend large amounts of money and resources to develop new technological and military techniques. However, they are all surpassed by very simple and inexpensive materials like improvised explosive devices (IOD), or by employing ambushes with light arms.

Nowadays, many states are struggling to deal with these kind of threats across wide the world. It is obvious that, to achieve success against asymmetric threats, required measures needs to be taken before the events. Otherwise, measures taken after the incidents, cannot compensate the losts.

Through history, besides the tactics and techniques of the periods, strategists seek for ways of overcoming the enemy by unexpected force, and in an unexpected time and place. In this respect many methods have been improvised.

Considering the very complex nature of this kind of warfare, a complex and sophisticated system such as a UAV can be one of the solutions against this type of threat. UAVs provide asymmetric advantages such as stealth, low visibility and engagement from a far distance. For this purpose, it is critical to understand the capabilities and capacities of these emerging systems in conjunction with asymmetric warfare.

\section{B. Unmanned Aerial Vehicles (Uav), Application Fields,} And Using Uavs in Accordance with Ikm

Unmanned Aerial Vehicles are defined as "a powered, aerial vehicle that does not carry a human operator, uses aerodynamic forces to provide vehicle lift, can fly autonomously or be piloted remotely, can be expendable or recoverable, and can carry a lethal or non-lethal payload" [2]. 
In military, Unmanned Aerial Vehicles (UAVs) are used in many fields. Some of them are:

1) Recce Missions: One of the basic functions of unmanned systems is the reconnaissance missions which provide real time intelligence to the operators in the field. These sytems can effectively monitor the desired sector of the operational area during day and night.

2) Target acquisition, confirmation and tracking: With the mounted cameras on these systems, it is possible to acquire, confirm ( along with the intelligence reports for that specific area) and if required, track a target during the day and night missions.

3) Engage/Kill a Target: The unmanned systems that carry ammunition and weapons provide the option to engage the target after being tracked and confirmed.

4) Maritime Missions: UAVs provide surface fire support, over the horizon target acquisition capability, categorization of ships, missile defense, anti sub-marine warfare capability, search and rescue and mine defense support during maritime missions and operations.

5) Electronic Warfare: UAVs have the capabilities of electronic attack, signal intelligence, directed energy weapons, electronic jamming, and sensor reconnaissance.

6) Chemical Recce: Unmanned systems can fly over CBRN contaminated areas, provide valuable recce and damage assessment for the operators.

7) PSYOPS and Special Operations: Unmanned systems can also be utilized in providing logistics to the special operators and psyops units (either planned or emergency cases) or dropping brochures over populations that we intend to effect.

8) Recce Missions in Urban Areas: Unmanned systems shoulder the role of providing control of streets and building tops for the operational units [3].

9) Logistics Support: It is possible to transport all classes of logistics to the units out in the field. For this purpose, rotarywing unmanned systems are mainly used. At the same time, this will be possible with the unmanned land systems as well by assigning certain check points along a path for that vehicle.

Beside these missions, UAVs are actively used in base security, directing friendly forces, detection, approval and tracking the threats, road security, convoy escorting, border patrolling, meteorological analysis, waypoint and landing point reconnaissance, directing indirect fire and close air support, combat damage assessment, radio and data transmitting [4].

From this point, with installing the wide area surveillance systems such as Argus to the long endurance UAVs, it will be possible to watch the areas that cannot be controlled by the forces, such as borders, and probable incident areas. Visions taken by the systems are transmitted to a databank. This data will be assessed effectively if it is classified properly beforehand. Unless, the whole data will go deep into information garbage.

\section{Information Knowledge Management}

Knowledge management (KM) comprises a range of strategies and practices used in an organization to identify, create, represent, distribute, and enable adoption of insights and experiences [5]. Information knowledge management is effectively used in media, computer technologies, public health and public order sectors.[5] Such insights and experiences comprise knowledge, either embodied in individuals or embedded in organizations as processes or practices[2], [3]. More recently, other fields have started contributing to KM research; these include information and media, computer science, public health, and public policy[4]. Along with this, knowledge management is a very important process in military especially in intelligence sector.

Many large companies and non-profit organizations have resources dedicated to internal KM efforts, often as a part of their business strategy, information technology, or human resource management department [5]. Several consulting companies also exist that provide strategy and advice regarding KM to these organizations [6].

Knowledge is central for the operational capability of unmanned systems. UAVs, either provide or look for some type of knowledge to be turned into intelligence in the operational area. With the mounted cameras and other sophisticated systems, UAVs attain critical intelligence for the warfighters. Rather than just being a piece of reconnaissance, UAVs can also store, categorize and if required, channel that information down the chain of command.

\section{FACE DETECTION PROGRAM AND INFORMATION KNOWLEDGE MANAGEMENT}

In face detection systems, face of a person is recorded from different view of aspects. These views are kept in the data bank of a computer program. With a program working in accordance with security cameras, when a suspected person is viewed, it then is compared with the photo in the data bank, and when they are matched, security units will be alarmed.

Currently, taken images are transferred to ground control stations and analysis of suspicious or wanted people by UAVs is carried out by an analyser personnel through examination of taken images.

Thanks to wide area surveillance systems, it is currently possible to observe very large areas continuously. Besides, detecting and diagnosing wanted or suspicious individuals when resolutions of the cameras of the wide area surveillance systems are enhanced well enough to make facial diagnosis. These images can be loaded to face and vehicle diagnosis programs. With a special program that can compare a person's face from different angles, it will be possible to compare it with the view in the data bank. This system can be used both in rural or urban terrain. But, although it is easy to make facial detection in the rural areas, it will remain a question how to achieve these kinds of diagnosis in highly populated ones.

Fig. 1 shows a sample photo which can be used in face detection programs [7].

Besides, interfering in wrong individuals may cause permanent anxiety within the public. But, prompt detention 
of the criminals will increase sense of trust within citizens. To prevent labor waste, the system needs to be run in coordination with intelligence units. Thus, UAVs can be sent to the areas which has possible threats.

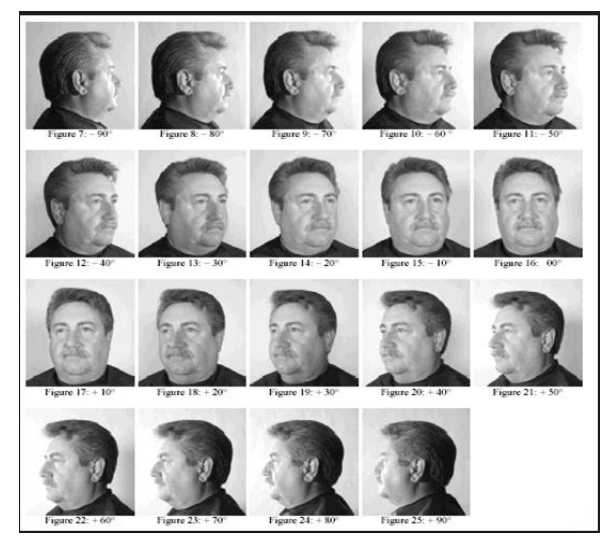

Fig. 1. Sample photos.

\section{Introducing The Guilty Personnel Profile to UAVS}

Machine learning is to make machines use the previous data and guess the alternatives in similar situations and to develop course of actions. With machine learning technology, specific behaviour profiles of people in several situations can be defined with computer programming languages. One of the most used areas is recognizing handwriting and transform it into computer form. In handwriting recognition, different types of letters in handwriting form are kept in a databank. When a person write onto a tablet PC or smart phone, or take an image of a handwriting, they are compared with the shapes in the databank and the best match appears in the screen.

Another sector is the road computers in cars. A car with a road computer can specify your driving habits and act as your wish. If a person is driving car wildly, the car will not change the shift until it overload the engine; and vice versa.

Likewise people show specific behavior profiles in different situations. Individuals behave different when they are happy from their behavior in their angry mood. From this point, a data bank of guilty people's behavior profiles can be created. Then, the individuals who show one of these behaviors is taken in an inspection process, and in case of another match occurs, security units can be activated with warning.

Visions obtained by wide area surveillance systems can be examined by a computer program and guilty profiles such as anxiety, rubbing hands, inspecting whereabouts..etc. can be detected. With this, even in the crowd, guilty can be detected. Supported with face detection program, detailed analysis can be done.

\section{USE OF LASER TeChNOLOGIES IN UAVS AGAINST Mines AND EODS}

It is very hard for UAVs to find EODs after they are laid down. Likewise, it is hard to detect a person who tied his body explosives. But, it will be very late to take measures after they are exploded. In the current situation, although mines and EODs can be detected by thermal cameras, the results are not conclusive.

One of the capabilities which has been used widely in recent years is laser technology. Laser technology not only can be used against asymmetric threats as improvised explosive devices (IED), but also it can be used against conventional threats such as air assaults, fire assaults. For example, when laser is embedded into radar, it is possible to detect and destroy IED's within the wide radar spectrum. UAV's are the only devices to survive while examining extensive theaters and engaging to the threats detected. The point here is that to mount laser technologies on a UAV is still a major problem according to its weight, size and energy resource. It is regarded that laser relaying technology which is being developed will overcome this problem. When it is accomplished, laser rays transmitted from an energy source will be stored and directed simultaneously into the region.

Thus, IEDs which are the main equipment used by terrorist organizations and non-state actors will be defeated by a new capability with a wide coverage spectrum.

\section{CONCLUSION}

Unmanned Aerial Vehicles are being used in both military and civilian life in a very broad range and thousands of terabyte of data is being stored. This data must be classified and stored due to place and time. Thus, it will be possible to reach the data of various time periods and observe the changes of a specific area. Unless, this data will turn into a data garbage and it will be very hard to utilize from it.

Another area of information knowledge management is that determining guilty and suspected individuals by help of face detection systems integrated with UAV visions.

With its increasing importance, Information knowledge management is effectively used in military. The use of knowledge management in UAVs will increase the benefits and will help the decision makers to detect the threat and to take measures.

\section{REFERENCES}

[1] Simetri. [Online]. Available: http://simetri.nedir.com/

[2] Secretary of Defence, Unmanned Aircraft Systems 2005-2030, pp. 1.

[3] H. İsa, "İnsansız Hava Araçlarına Genel Bir Bakış," Turkish Armed Forces Journal, April 2010.

[4] GLADE, David, Lt. Col., USAF "Unmanned Aerial Vehicles: Implications for Military Operations," Center for Strategy and Technology - Air War College-Air University-Maxwell Air Force Base, Alabama, US.

[5] Knowledge_management. [Online]. Available: http://en.wikipedia.org/wiki/Knowledge_management\#cite_note-2, Access date: 01 June 2013

[6] Introduction to Knowledge Management, University of North Carolina at Chapel Hill.

[7] Face recognition an introduction. [Online]. Available: http://alitarhini.wordpress.com/2010/12/05/face-recognition-an-introd uction/

Alper Alparslan Eker is a major in Turkish Army, who was born in 1977 in Ankara, Turkey. He graduated from Turkish Army War Academy in 1999. He has worked in several units in Turkish Army and he finished Turkish Army War College in 2008 and earned postgraduate degree. He has another postgraduate degree in Turkish Republic History. He has been working as an Instructor in Turkish Army War College since 2012. He is married and have one child. He knows English as a foreign language. 
Saban Adana is a captain in Turkish Army, who was born in 1979 in Eskisehir, Turkey. He graduated from United States Military Academy, Westpoint, in 2002. He has worked in several units in Turkish Army. He has a postgraduate degree from Naval Postgraduate School, Monterey, California, USA on National Security Affairs in Middleeast. He will have finished Turkish Army War College and earned postgraduate degree by the end of July, 2013. He is married and have one child. He knows English as a foreign language.
Ísa Haskologlu is a captain in Turkish Army, who was born in 1981 in Malatya, Turkey. He graduated from Turkish Army War Academy in 2003. He has worked in several units in Turkish Army. He is a postgraduate studen officer in Turkish Army War College. He will have finished Turkish Army War College and earned postgraduate degree by the end of July, 2013. He is married and have two children. He knows English as a foreign language. 